\title{
Family as a Context for Child Development: Mothers with the FMR1 Premutation and Their Children with Fragile X Syndrome
}

\author{
Katherine Bangert, Ph.D., CCC-SLP, ${ }^{1,2}$ Carly Moser, B.A., ${ }^{1}$ \\ Laura Friedman, Ph.D., CCC-SLP, ${ }^{1}$ and Jessica Klusek, Ph.D., CCC-SLP ${ }^{1}$
}

Fragile $\mathrm{X}$ syndrome (FXS) is a genetic disorder caused by changes of the FMR1 gene that is passed along among families. A range of developmental processes may be impacted with wide variation in abilities across individuals with FXS. Mothers of children with FXS are often carriers of a "premutation" expansion on the FMR1 gene, which is associated with its own clinical phenotype. These maternal features may increase individual and family vulnerabilities, including increased risk for depression and anxiety disorders and difficulties in social and cognitive ability. These characteristics may worsen with age, and potentially interact with a child's challenging behaviors and with family dynamics. Thus, families of children with FXS may experience unique challenges related to genetic risk, manifested across both children and parents, that should be considered in therapeutic planning to optimize outcomes for children and their families. In this article, we review core features of the FMR1 premutation as expressed in mothers and aspects of the family environment that interface with developmental outcomes of children with FXS. Recommendations for family-centered support services are discussed.

KEYWORDS: fragile $X$ premutation, fragile $X$ syndrome, fragile $X$ carriers, mother-child associations

Learning Outcomes: As a result of this activity, the reader will be able to (1) identify key characteristics of the FMR1 premutation phenotype; (2) describe the significance of potential premature age decline in this population; and (3) explain the relevance of maternal FMR1 premutation characteristics in terms of clinical outcomes in children.

\footnotetext{
${ }^{1}$ Department of Communication Sciences and Disorders, University of South Carolina, Columbia, South Carolina; ${ }^{2}$ Department of Psychology, University of South Carolina, Columbia, South Carolina.

Address for correspondence: Jessica Klusek, Ph.D., CCC-SLP, Department of Communication Sciences and Disorders, University of South Carolina, 1705 College Street, Columbia, SC 29208 (e-mail: klusek@mailbox.sc.edu).
}

Neurogenetic Disorders: Exploring the Role of Context and Communication Partners; Guest Editor, Laura J. Mattie, Ph.D.

Semin Speech Lang 2021;42:277-286. (C) 2021. Thieme. All rights reserved. Thieme Medical Publishers, Inc., 333 Seventh Avenue, 18th Floor, New York, NY 10001, USA

DOI: https://doi.org/10.1055/s-0041-1730988.

ISSN 0734-0478. 
Fragile X syndrome (FXS) is an inherited genetic disorder that affects approximately 1 in 7,000 males and 1 in 11,000 females worldwide. ${ }^{1}$ The syndrome represents the most common inherited form of intellectual disability and the most common single-gene disorder associated with autism spectrum disorder (ASD). Nearly all males with FXS and about a third of females have intellectual disability, ${ }^{2}$ and rates of comorbid ASD are estimated at 55 to $89 \%$ in males and 10 to $14 \%$ in females. ${ }^{3-6}$ Other core features of the FXS phenotype include anxiety, hyperactivity, hyperarousal, and executive dysfunction. ${ }^{7-10}$ Speech-language pathologists are often involved in clinical and/or educational services for this population, given that impairments in speech, language, and literacy skills are common in FXS. ${ }^{11-16}$ Because FXS is a genetic disorder that is passed through families, family members of individuals with FXS may also experience clinical involvement, including mothers who are genetic carriers of the condition. In this article, we review the core clinical symptoms experienced by mothers of children with FXS in relation to the developmental outcomes of children with FXS and implications for service provision.

FXS is caused by an abnormal expansion of a CGG trinucleotide sequence on the fragile $\mathrm{X}$ mental retardation-1 (FMR1) gene located on the $\mathrm{X}$ chromosome. ${ }^{17-19}$ In most individuals in the general population, the FMR1 CGG sequence repeats between 10 and 54 times. FXS occurs when the CGG sequence exceeds 200 repeats, which causes the gene to "shut down" and disrupts production of fragile $\mathrm{X}$ mental retardation protein (FMRP), a protein that is necessary for cognitive development and function. ${ }^{20-22}$ A notable feature of FXS that distinguishes it from other common neurogenic syndromes such as Down syndrome is that FXS is a heritable condition where children with FXS inherit the condition from their mothers who are genetic carriers. Mothers of children with FXS, unless they have FXS themselves, are known genetic carriers of a smaller CGG expansion of 55 to 200 repeats, called the FMR1 "premutation." The FMR1 premutation is relatively common in the general population; approximately 1:148-291 females and 1:290-855 males worldwide possess the premutation, although many of these individuals are unaware of their genetic status. $1,20,23$ While both men and women can carry the FMR1 premutation, with very few exceptions fathers cannot pass FXS to their children.,20,21 When transmitted from fathers, the FMR1 premutation CGG expansion is stable and does not expand further ${ }^{20,21,24}$; therefore, fathers pass the FMR1 premutation to all of their daughters and none of their sons (sons will inherit their father's $Y$ chromosome). Mothers, on the other hand, have approximately a 50/50 chance of passing the expanded CGG repeat sequence to all of their children, who may inherit either the FMR1 premutation or the "full mutation" of FXS if the CGG sequence expands beyond 200 repeats. Given this inheritance pattern, except for very rare exceptions, FXS is always inherited from mothers. Therefore, the clinical problems experienced by mothers who carry the FMR1 premutation have broader implications, as they can affect outcomes for both the mother and her children with FXS. In this article, we focus on the clinical consequences of the FMR 1 premutation in mothers and implications for children and families.

Historically, mothers with the FMR1 premutation were thought to be "silent carriers" who were clinically unaffected. Over the last two decades, it has become increasingly clear that mothers with the FMR1 premutation are at heightened susceptibility for experiencing adverse phenotypes themselves. Two welldocumented disorders that are caused by the FMR1 premutation include fragile $\mathrm{X}$-associated primary ovarian insufficiency (FXPOI) and fragile $\mathrm{X}$-associated tremor/ataxia syndrome (FXTAS). FXPOI is a condition characterized by early menopause and fertility problems, documented in approximately $20 \%$ of women with the FMR1 premutation. ${ }^{25}$ FXTAS is a late-onset neurodegenerative disease characterized by movement and cognitive problems that affects approximately $15 \%$ of women with the FMR1 premutation in old age. ${ }^{7,26}$ In addition to FXPOI and FXTAS, mothers with the FMR1 premutation are at an increased risk for a wide range of other medical, cognitive, 
and psychiatric symptoms, including mood and anxiety disorders, executive dysfunction, and social-communication differences such as poor eye contact and conversational pragmatic language deficits. ${ }^{27-30}$ These maternal features may increase individual and family vulnerabilities and should be considered in therapeutic planning to optimize outcomes for both children with FXS and their families. Below we review core mental health, pragmatic language, and executive function features of the FMR1 premutation as expressed in mothers, with a focus on the FMR1 premutation phenotype as an aspect of the family environment that may interface with developmental outcomes of children with FXS.

\section{THE FMR1 PREMUTATION PHENOTYPE IN MOTHERS}

\section{Mental Health Features}

Women with the FMR1 premutation are at increased risk for mental health disorders, including anxiety and depression. ${ }^{26,31-34}$ In one study comparing mothers with the FMR1 premutation $(n=93)$ to a large national database $(n=2,159), 43 \%$ of mothers with the FMR1 premutation had experienced a major depressive episode in their lifetime, which was significantly elevated compared with the rate of $32 \%$ of the women from the comparison sample. ${ }^{32}$ This report also detected elevated rates of lifetime panic disorder (9\%) and current agoraphobia (3\%) in mothers with the FMR1 premutation. ${ }^{32}$ In a related report following a largely overlapping sample longitudinally, Roberts et $\mathrm{al}^{33}$ found that the rates of depression and anxiety increased significantly in mothers with the FMR1 premutation across middle age. In a 3-year period, the rates of lifetime major depressive disorder increased from 46 to $54 \%$ and the rates of anxiety disorders increased from 28 to $35 \%$. These findings suggest a striking increase in the rates of mental health disorders in mothers with the FMR1 premutation across middle adulthood and have implications for service delivery, as they suggest that many mothers with the FMR1 premutation may be struggling to manage their own clinical problems at a time when they are also assuming immense caregiver burden related to parenting a child with FXS.

Both biological and environmental factors are thought to contribute to risk for mental health disorders in mothers with the FMR1 premutation. For instance, mothers who carry the FMR1 premutation demonstrate varied repeat lengths of the CGG sequence. In research, premutation CGG repeat expansions are often categorized as low premutation repeats between approximately 55 and 79 , midrange expansions of approximately 80 and 110 CGG repeats, and high premutation expansions of approximately 110 and 200 repeats (see Table 1). Several reports have shown that mothers who carry midrange CGG repeat lengths may be more likely to experience depression and anxiety than those with higher or lower premutation repeat numbers. $^{32,35}$ Environmental factors, such as child problem behavior and negative life stressors, may also contribute to mental health risk in an additive or interactive manner. For example, having more than one child with FXS or a child who displays increased problem behaviors is associated with increased anxiety and depression risk. ${ }^{32,33}$ The relationship between child problem behaviors and maternal mental health risk is likely bidirectional, as studies also suggest that children with FXS demonstrate more challenging behaviors when mothers have increased symptoms of depression or anxiety. ${ }^{31-33,36,37}$ Thus, a cyclical pattern may occur where behavioral challenges in children with FXS lead to increased parenting stress and poor

\section{Table 1 FMR1 CGG Repeat Categories}

\begin{tabular}{ll}
\hline CGG repeat category & CGG repeat length \\
\hline No expansion on & $10-54$ \\
FMR1 ("normal") & \\
Premutation & $55-200$ \\
$\quad$ Low premutation & $\sim 55-79$ \\
Midrange premutation & $\sim 80-110$ \\
$\quad$ High premutation & $\sim 110-200$ \\
Full mutation & $>200$ \\
\hline
\end{tabular}

Note: Premutation subcategories reflect potential zones of vulnerability that have been reported in emerging research, and are approximate. ${ }^{56,59,72}$ A "full mutation" CGG expansion on FMR1 is associated with fragile $X$ syndrome. 
maternal mental health, which in turn may lead to further increases in challenging behaviors displayed by children. Awareness of the impact of maternal mental health symptoms on the family environment and on child behavior can assist clinicians in prioritizing referrals for psychological counseling and prescribing interventions that are a good match with family characteristics.

\section{Pragmatic Language Features}

Pragmatic language difficulties have also been noted in mothers with the FMR1 premutation. When compared with mothers of children with typical development or ASD, mothers with the FMR1 premutation show more pragmatic violations during conversation, which include perseverating on topics, talking too much, talking too little, providing too many details, as well as exhibiting difficulties with suprasegmental features of speech, such as use of inappropriate volume and odd intonation. ${ }^{29,38}$ Although the pragmatic language difficulties observed in the FMR1 premutation are typically mild, growing evidence suggests that these features are related to the developmental outcomes of children with FXS. Specifically, maternal pragmatic language difficulties are associated with poorer receptive vocabulary, reduced expressive syntax skills, and increased ASD symptoms in children with FXS. ${ }^{28,39}$ This is possibly due to the child being less able to benefit and learn from interactions with their caregivers when they are exposed to ineffective language models, a notion that aligns with a transactional model of developmental theory. Under this model, development is informed by reciprocal exchanges between the child and their social context. ${ }^{40}$

High-quality parental interactions that are emotionally positive and verbally responsive are known to support child engagement, responsiveness, and learning and are associated with enhanced language outcomes in children with FXS. ${ }^{41-44}$ For example, Warren et $\mathrm{al}^{44}$ investigated responsivity in mothers of children with FXS, as characterized by reciprocal maternal behaviors such as comments, gestures, requests, and recasts during interactions with their child. A more responsive maternal interaction style robustly predicted later expressive and receptive language and overall communicative ability in young children with FXS. These findings have been replicated into late childhood and adolescence. ${ }^{41}$ Related work suggests that low-quality asynchronous interactions between mothers and their children with FXS are associated with increased maternal pragmatic language difficulties. ${ }^{45}$ These findings suggest that maternal pragmatic language skills are a relevant aspect of the child's social learning environment that may influence developmental outcomes of children with FXS via reduced quality of the mother-child interactions. ${ }^{42-44}$

Finally, it is notable that pragmatic language difficulties in mothers with the FMR1 premutation are also tied to the health and wellbeing of mothers themselves. Mothers who experience high levels of pragmatic language difficulty are more likely to report loneliness, depression, decreased life satisfaction, and poorer quality of family relationships. ${ }^{46}$ Associations between the pragmatic language skills of mothers with the FMR1 premutation, their own well-being, and their children's outcomes underscore the importance of family-centered practices that recognize the transactional nature of family interactions and relationships and individualize services to the needs of the family as a whole.

\section{Executive Function and Other Cognitive and Linguistic Features}

Deficits in cognitive skills such as executive functions (e.g., attention, working memory, inhibition, organization), visuospatial processing, arithmetic, and mathematical reasoning have been documented in a subset of women with the FMR1 premutation. ${ }^{4-54}$ These deficits range in severity and are not universal, which highlights the need to better understand personalized risk factors that can predict which individuals will experience symptoms. Perhaps the most widely documented cognitive difficulty in women with the FMR1 premutation is in response inhibition, an aspect of executive function that reflects the ability to inhibit prepotent (e.g., automatic) thoughts and behaviors. ${ }^{30,55-58}$ Relative to mothers of children with ASD and children with typical development, women with the FMR1 premutation 
show poorer performance on tasks requiring the suppression of prepotent verbal, visual, and oculomotor responses. ${ }^{28,30,55,57-59}$ Vulnerability for inhibition deficits in women with the FMR1 premutation appears to be tied to genetic risk. For example, in a large study of over 100 mothers with the FMR1 premutation, Klusek et $\mathrm{al}^{56}$ found that mothers who carried midrange CGG lengths of approximately 80 to 110 repeats showed increased vulnerability for verbal inhibition deficits relative to those with higher or lower premutation CGG expansions. Specifically, latency was longest (indicating poorer inhibition skills) for mothers with midrange CGG repeats relative to those with lower $(<80)$ or higher $(\sim 110-120)$ CGG repeat lengths. Increased latency was also observed among mothers who carried high CGG repeats of greater than 120, suggesting that high CGG repeat lengths may also be associated with increased vulnerability. Older age was also associated with poorer inhibition skills. Fig. 1 depicts the relationship between CGG repeat lengths with response latency (inhibition) across mothers of various ages. ${ }^{56}$

Similar CGG-dependent associations have been detected in the presentation of language disfluencies, which are theoretically tied to deficits in inhibitory control. ${ }^{60}$ In language samples, mothers with the FMR1 premutation tend to produce more disfluencies (i.e., word and phrase repetitions, interjections, filled pauses) relative to mothers of children with other neurodevelopmental disorders such as $\mathrm{ASD},{ }^{30,59,61}$ with the highest rate of disfluencies observed among mothers who carried midrange CGG repeat lengths $(\sim 80-110))^{59}$ Therefore, there is converging evidence that clinical features of the FMR1 premutation may have increased severity among those with midrange CGG repeat lengths, suggesting that the length of the premutation CGG expansion may represent a personalized risk factor that may be useful in targeting prevention efforts. ${ }^{30,55,59,61}$ With genetic testing becoming increasingly accessible, it is common for mothers with the FMR1 premutation to know the length of their CGG repeat expansion. As understanding of CGG-associated risk continues to grow, it may soon be possible to apply information about individual CGG repeat numbers to better understand personalized risk and tailor prevention/treatment accordingly.

Older age also appears to be a risk factor for cognitive involvement in mothers with the FMR1 premutation. A growing number of cross-sectional studies have detected associations between older age and the expression of executive dysfunction symptoms, suggesting that mothers with the FMR1 premutation may experience premature age-related decline. For example, in a study of 134 mothers with the

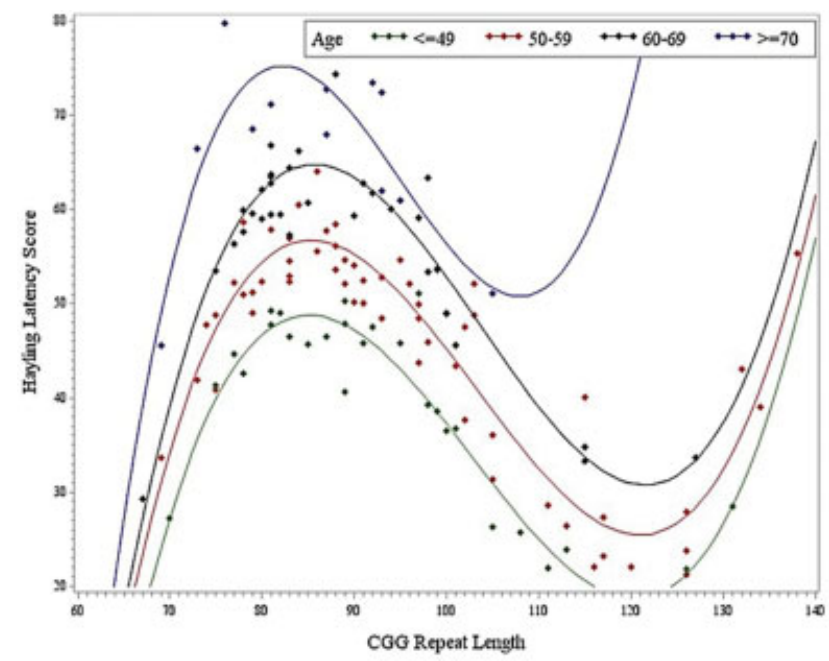

Figure 1 Effect of age and CGG repeat length on response inhibition skills. Note: Longer latency on the Hayling reflects poorer inhibition skills. (Reproduced with permission from Klusek et al, ${ }^{56}$ Copyright 2020 by Elsevier.) 
FMR1 premutation aged 39 to 88 years, Klusek et $\mathrm{al}^{56}$ documented a significant association between older age and verbal inhibition deficits, with findings suggesting that age-related decline may begin as early as the fourth decade of life and the severity of deficits increase with each passing decade (see Fig. 1 for illustration of age effects).

Other reports have documented similar age effects in the areas of oculomotor inhibition, ${ }^{55}$ language fluency, ${ }^{30}$ and magnitude comparison and numerical enumeration performance. ${ }^{49,50}$ Importantly, in each of these reports, the age effects were not observed in control samples of mothers of children with ASD or typical development and thus are specific to women with the FMR1 premutation, underscoring that the age-related changes observed in women with the FMR1 premutation are atypical and diverge from the patterns observed in healthy aging. ${ }^{30,49,50,55}$ Longitudinal studies will be important in future work to confirm these early findings based on cross-sectional data and to draw robust longitudinal trajectories. A recent report by Bredin-Oja et $\mathrm{al}^{61}$ represented one of the few longitudinal investigations of mothers with the FMR1 premutation conducted to date and provided further support for age-related decline in this group. The researchers followed up 38 mothers with the FMR1 premutation, aged 36 to 55 years at the last data point, longitudinally over a span of 8 years. As the mothers aged, they made more word retrieval errors and produced fewer words during language samples, providing further support for age-related decline in cognitive-linguistic skills associated with the FMR1 premutation. Future longitudinal work will further delineate the agerelated phenotype of the FMR1 premutation, particularly as mothers enter old age.

\section{CLINICAL CONSIDERATIONS}

Because FXS is a familial disorder, siblings may also inherit FXS or the FMR1 premutation. $^{62}$ Approximately $20 \%$ of families have more than one child affected by FXS. ${ }^{63}$ Clinicians should be aware of the familial nature of FXS and monitor siblings of children with FXS for early signs of autism, language delay, social impairment, and intellectual disability. Across populations and diagnoses, family and other environmental factors can be sources of risk or resilience for a child's development. Within the context of FXS, variations in the home environment related to genetic risk among family members may be an influencing factor in the selection of therapies that fit the needs of the child and family. For example, the selection of parent-implemented intervention approaches may facilitate the use of parent coaching strategies to help parents build rich communicative interactions into their child's daily routines and provide scaffolding and reinforcement for their children's communicative attempts. These approaches appear promising in $\mathrm{FXS}^{64-66}$; for detailed discussion of parentimplemented language interventions, see the study by Bullard and Abbeduto.

Another factor that may influence the expression of FMR1 phenotype characteristics is age. Notably, emerging research suggests that mothers with the FMR1 premutation may begin to experience age-related decline as young as their 40 s, with symptoms worsening with age. ${ }^{30,49,50}$ Evidence of age-related decline in mothers with the FMR1 premutation is significant because mothers may experience worsening symptoms at a period in their life when parenting responsibilities remain high. Individuals with FXS tend to continue living with and require care from their parents into adulthood. In a survey of 328 adults with FXS aged 22 and older, 70\% of men and $50 \%$ of women were reported to reside with their parents, and high or very high levels of assistance in everyday life were required by $57 \%$ of the men and $19 \%$ of the women with FXS. ${ }^{67} \mathrm{~A}$ quarter of the women and over half of the men with FXS were reported to have low or very low levels of independence, as defined by employment, friendships, and engagement in leisure activities, as well as the need for assistance in daily living. Thus, adults with FXS may continue to live with and depend on their aging parents, who themselves may be struggling with increasing health issues as they age. FXS is a lifelong disorder and the need for support services does not end once primary education is complete. 
Another critical consideration, and an area of research lacking in the field, is that as children with FXS grow into adolescents and young adults, they may "age out" of speech and language intervention services. This is perhaps because they did not previously demonstrate benefits from therapy, or clinicians mistakenly believe they are past the age of improving speech and language abilities. Neither is appropriate reason for dismissal from speech-language services (see articles by Brady et $\mathrm{al}^{68}$ and the National Joint Committee for the Communication Needs of Persons With Severe Disabilities, ${ }^{69}$ for a review). Provision of services, including speech and language therapy, declines across age in FXS. In a national U.S. survey of over 1,000 families of children with FXS, very few individuals with FXS continued to receive allied health therapies after the age of 20 years. ${ }^{70}$ The percentage of children receiving speech and language services dropped sharply as children aged, with approximately $70 \%$ of $6-$ to 10-year-olds with FXS receiving speechlanguage services, approximately $55 \%$ of 10 - to 15-year-olds, and approximately $40 \%$ of 16- to 20-year-olds, suggesting that many children with FXS are dismissed from speechlanguage pathologists' caseloads prior to the completion of elementary school. ${ }^{70}$ Adolescents and adults with FXS, especially those with more complex phenotypes (e.g., increased mental health symptoms and poorer functioning skills) may benefit from services aimed toward improving functional daily living and social interaction skills. ${ }^{67}$ In sum, to maximize individual and family outcomes, clinicians should strongly consider the continuation of services in adolescence and early adulthood to support the family during the transitory phase that follows completion of $\mathrm{K}-12$ education. Families may actually be losing services at a time when families need more support, which is compounded by premutation-associated symptoms that may increase with age. ${ }^{49,71}$ Implementing appropriate transition plans for postsecondary school or work and ensuring service continuity should be therapeutic priorities. The complex interaction between biology, family environment, parent-child interactions, and developmental outcomes may intensify this populations' need for services across the lifespan.

\section{CONCLUSION}

FXS has a known genetic inheritance, and mothers of children with FXS may be vulnerable to adverse phenotypes associated with their genetic status as carriers of the FMR1 premutation. FMR1 premutation-associated risks may result in unique challenges for families. Understanding the range of clinical effects experienced by mothers with the FMR1 premutation is important for identifying familycentered prevention and intervention practices that meet the specific needs of families of children with FXS. Mother's mental health and stressors in the family related to child behaviors are important factors when tailoring a home-based approach. It may be appropriate to make referrals to mental health providers, genetic counseling, and other medical experts in some cases. Clinicians who are knowledgeable about the disorder can ensure families are well-educated about the family of fragile $\mathrm{X}$-associated conditions, can provide appropriate services, and can make recommendations for referral when appropriate.

\section{DISCLOSURES}

The authors have no relevant financial or nonfinancial relationships to disclose.

\section{CONFLICT OF INTEREST}

None declared.

\section{ACKNOWLEDGMENTS}

This research was supported by the National Institutes of Health (1R21DC017804-01, PI: Klusek 1R03HD098291-0, PI Klusek; 2R01HD024356, PI: Abbeduto).

\section{REFERENCES}

1. Hunter J, Rivero-Arias O, Angelov A, Kim E, Fotheringham I, Leal J. Epidemiology of fragile X syndrome: a systematic review and meta-analysis. Am J Med Genet A 2014;164A(07):1648-1658

2. Rousseau F, Heitz D, Tarleton Jet al.. A multicenter study on genotype-phenotype correlations in the fragile $\mathrm{X}$ syndrome, using direct diagnosis with probe StB12.3: the first 2,253 cases. Am J Hum Genet 1994;55(02):225-237 
3. Abbeduto L, Thurman AJ, McDuffie Aet al.. ASD comorbidity in fragile $\mathrm{X}$ syndrome: symptom profile and predictors of symptom severity in adolescent and young adult males. J Autism Dev Disord 2019;49(03):960-977

4. Clifford S, Dissanayake C, Bui QM, Huggins R, Taylor AK, Loesch DZ. Autism spectrum phenotype in males and females with fragile $\mathrm{X}$ full mutation and premutation. J Autism Dev Disord 2007;37(04):738-747

5. Haebig E, Sterling A, Barton-Hulsey A, Friedman L. Rates and predictors of co-occurring autism spectrum disorder in boys with fragile $\mathrm{X}$ syndrome. Autism Dev Lang Impair 2020; (epub ahead of print) . Doi: 10.1177/239694152 0905328

6. Harris SW, Hessl D, Goodlin-Jones B et al. Autism profiles of males with fragile $\mathrm{X}$ syndrome. Am J Ment Retard 2008;113(06):427-438

7. Hagerman RJ, Protic D, Rajaratnam A, SalcedoArellano MJ, Aydin EY, Schneider A. Fragile Xassociated neuropsychiatric disorders (FXAND). Front Psychiatry 2018;9:564

8. Klusek J, Martin GE, Losh M. Physiological arousal in autism and fragile $\mathrm{X}$ syndrome: group comparisons and links with pragmatic language. Am J Intellect Dev Disabil 2013;118(06): 475-495

9. Ezell J, Hogan A, Fairchild A et al. Prevalence and predictors of anxiety disorders in adolescent and adult males with autism spectrum disorder and fragile X syndrome. J Autism Dev Disord 2019; 49(03):1131-1141

10. Schmitt LM, Shaffer RC, Hessl D, Erickson C. Executive function in fragile $\mathrm{X}$ syndrome: a systematic review. Brain Sci 2019;9(01):E15

11. Price J, Roberts J, Vandergrift N, Martin G. Language comprehension in boys with fragile $\mathrm{X}$ syndrome and boys with Down syndrome. J Intellect Disabil Res 2007;51(Pt 4):318-326

12. Roberts JE, Mirrett P, Anderson K, Burchinal M, Neebe E. Early communication, symbolic behavior, and social profiles of young males with fragile $\mathrm{X}$ syndrome. Am J Speech Lang Pathol 2002; 11:295-304

13. Klusek J, Martin GE, Losh M. A comparison of pragmatic language in boys with autism and fragile X syndrome. J Speech Lang Hear Res 2014;57(05): 1692-1707

14. Adlof SM, Klusek J, Shinkareva SV, Robinson ML, Roberts JE. Phonological awareness and reading in boys with fragile $\mathrm{X}$ syndrome. J Child Psychol Psychiatry 2015;56(01):30-39

15. Finestack LH, Abbeduto L. Expressive language profiles of verbally expressive adolescents and young adults with Down syndrome or fragile $\mathrm{X}$ syndrome. J Speech Lang Hear Res 2010;53(05): 1334-1348
16. Barnes E, Roberts J, Long $\mathrm{SH}$ et al. Phonological accuracy and intelligibility in connected speech of boys with fragile $\mathrm{X}$ syndrome or Down syndrome. J Speech Lang Hear Res 2009;52(04):1048-1061

17. Verkerk AJ, Pieretti M, Sutcliffe JS et al. Identification of a gene (FMR-1) containing a CGG repeat coincident with a breakpoint cluster region exhibiting length variation in fragile $\mathrm{X}$ syndrome. Cell 1991;65(05):905-914

18. Johnson CJ, Beitchman JH, Brownlie EB. Twentyyear follow-up of children with and without speech-language impairments: family, educational, occupational, and quality of life outcomes. Am J Speech Lang Pathol 2010;19(01):51-65

19. Hersh JH, Saul RA, Saal HMet al;Committee on Genetics. Health supervision for children with fragile X syndrome. Pediatrics 2011;127(05):994-1006

20. Tassone F, Hagerman RJ, Chamberlain WD, Hagerman PJ. Transcription of the FMR1 gene in individuals with fragile $\mathrm{X}$ syndrome. Am J Med Genet 2000;97(03):195-203

21. Hagerman RJ, Berry-Kravis E, Hazlett HC et al. Fragile X syndrome. Nat Rev Dis Primers 2017;3 (01):17065

22. Hagerman PJ, Hagerman RJ. Fragile X syndrome. In: Howlin P, Udwin Oeds.. Cambridge Child and Adolescent Psychiatry: Outcomes in Neurodevelopmental and Genetic Disorders. Cambridge, MA: Cambridge University Press; 2002:198-219

23. Seltzer MM, Baker MW, Hong J, Maenner M, Greenberg J, Mandel D. Prevalence of CGG expansions of the FMR1 gene in a US population-based sample. Am J Med Genet B Neuropsychiatr Genet 2012;159B(05):589-597

24. Nolin SL, Lewis FA III, Ye LL et al. Familial transmission of the FMR1 CGG repeat. Am J Hum Genet 1996;59(06):1252-1261

25. Sullivan AK, Marcus M, Epstein MP et al. Association of FMR1 repeat size with ovarian dysfunction. Hum Reprod 2005;20(02):402-412

26. Rodriguez-Revenga L, Madrigal I, Pagonabarraga $\mathrm{J}$ et al. Penetrance of FMR1 premutation associated pathologies in fragile $\mathrm{X}$ syndrome families. Eur J Hum Genet 2009;17(10):1359-1362

27. Del Hoyo Soriano L, Thurman AJ, Harvey DJ, Ted Brown W, Abbeduto L. Genetic and maternal predictors of cognitive and behavioral trajectories in females with fragile $\mathrm{X}$ syndrome. J Neurodev Disord 2018;10(01):22

28. Klusek J, McGrath SE, Abbeduto L, Roberts JE. Pragmatic language features of mothers with the FMR1 premutation are associated with the language outcomes of adolescents and young adults with fragile X syndrome. J Speech Lang Hear Res 2016;59(01):49-61

29. Losh M, Klusek J, Martin GE, Sideris J, Parlier M, Piven J. Defining genetically meaningful language and personality traits in relatives of individuals with 
fragile $\mathrm{X}$ syndrome and relatives of individuals with autism. Am J Med Genet B Neuropsychiatr Genet 2012;159B(06):660-668

30. Sterling AM, Mailick M, Greenberg J, Warren SF, Brady N. Language dysfluencies in females with the FMR1 premutation. Brain Cogn 2013;82(01): 84-89

31. Bailey DB Jr, Sideris J, Roberts J, Hatton D. Child and genetic variables associated with maternal adaptation to fragile $\mathrm{X}$ syndrome: a multidimensional analysis. Am J Med Genet A 2008;146A(06): 720-729

32. Roberts JE, Bailey DB Jr, Mankowski J et al. Mood and anxiety disorders in females with the FMR1 premutation. Am J Med Genet B Neuropsychiatr Genet 2009;150B(01):130-139

33. Roberts JE, Tonnsen BL, McCary LM, Ford AL, Golden RN, Bailey DB Jr. Trajectory and predictors of depression and anxiety disorders in mothers with the FMR1 premutation. Biol Psychiatry 2016; 79(10):850-857

34. Kenna HA, Tartter M, Hall SS et al. High rates of comorbid depressive and anxiety disorders among women with premutation of the FMR1 gene. Am J Med Genet B Neuropsychiatr Genet 2013;162B (08):872-878

35. Seltzer MM, Barker ET, Greenberg JS, Hong J, Coe C, Almeida D. Differential sensitivity to life stress in FMR1 premutation carrier mothers of children with fragile $\mathrm{X}$ syndrome. Health Psychol 2012;31(05):612-622

36. Hessl D, Dyer-Friedman J, Glaser B et al. The influence of environmental and genetic factors on behavior problems and autistic symptoms in boys and girls with fragile X syndrome. Pediatrics 2001; 108(05):E88

37. Greenberg J, Seltzer M, Baker J et al. Family environment and behavior problems in children, adolescents, and adults with fragile $\mathrm{X}$ syndrome. Am J Intellect Dev Disabil 2012;117(04):331-346

38. Klusek J, Fairchild AJ, Roberts JE. Vagal tone as a putative mechanism for pragmatic competence: an investigation of carriers of the FMR1 premutation. J Autism Dev Disord 2019;49(01):197-208

39. Losh M, Martin GE, Klusek J, Hogan-Brown AL, Sideris J. Social communication and theory of mind in boys with autism and fragile $\mathrm{x}$ syndrome. Front Psychol 2012;3:266

40. Sameroff AJ, Fiese BH. Handbook of Early Childhood Intervention. 2nd ed.Cambridge, MA: Cambridge University Press; 2000

41. Brady NC, Fleming K, Bredin-Oja SL, FieldingGebhardt H, Warren SF. Language development from early childhood to adolescence in youths with fragile X syndrome. J Speech Lang Hear Res 2020; 63(11):3727-3742

42. Ingersoll B, Gergans S. The effect of a parentimplemented imitation intervention on spontane- ous imitation skills in young children with autism. Res Dev Disabil 2007;28(02):163-175

43. Sterling AM, Warren SF, Brady N, Fleming K. Influences on maternal responsivity in mothers of children with fragile $\mathrm{X}$ syndrome. Am J Intellect Dev Disabil 2013;118(04):310-326

44. Warren SF, Brady N, Sterling A, Fleming K, Marquis J. Maternal responsivity predicts language development in young children with fragile $\mathrm{X}$ syndrome. Am J Intellect Dev Disabil 2010;115 (01):54-75

45. Moser C, Mattie L, Abbeduto L, Klusek J. The FMR1 premutation phenotype and mother-youth synchrony in fragile X syndrome. Am J Intellect Disabil. In press

46. Klusek J, Thurman AJ, Abbeduto L. Maternal pragmatic language difficulties in the FMR1 premutation and the broad autism phenotype: associations with individual and family outcomes. J Autism Dev Disord 2021; (epub ahead of print) . Doi: 10.1007/s10803-021-04980-3

47. Semenza C, Bonollo S, Polli R et al. Genetics and mathematics: FMR1 premutation female carriers. Neuropsychologia 2012;50(14):3757-3763

48. Lachiewicz AM, Dawson DV, Spiridigliozzi GA, McConkie-Rosell A. Arithmetic difficulties in females with the fragile $\mathrm{X}$ premutation. Am J Med Genet A 2006;140(07):665-672

49. Goodrich-Hunsaker NJ, Wong LM, McLennan Y et al. Young adult female fragile $\mathrm{X}$ premutation carriers show age- and genetically-modulated cognitive impairments. Brain Cogn 2011;75(03): 255-260

50. Goodrich-Hunsaker NJ, Wong LM, McLennan Y et al. Adult female fragile $\mathrm{X}$ premutation carriers exhibit age- and CGG repeat length-related impairments on an attentionally based enumeration task. Front Hum Neurosci 2011;5:63

51. Kraan CM, Hocking DR, Bradshaw JL et al. Neurobehavioural evidence for the involvement of the FMR1 gene in female carriers of fragile $\mathrm{X}$ syndrome. Neurosci Biobehav Rev 2013;37(03): 522-547

52. Hunter JE, Allen EG, Abramowitz A et al. No evidence for a difference in neuropsychological profile among carriers and noncarriers of the FMR1 premutation in adults under the age of 50. Am J Hum Genet 2008;83(06):692-702

53. Hunter JE, Epstein MP, Tinker SW, Abramowitz A, Sherman SL. The FMR1 premutation and attention-deficit hyperactivity disorder (ADHD): evidence for a complex inheritance. Behav Genet 2012;42(03):415-422

54. Hashimoto R, Backer KC, Tassone F, Hagerman RJ, Rivera SM. An fMRI study of the prefrontal activity during the performance of a working memory task in premutation carriers of the fragile $\mathrm{X}$ mental retardation 1 gene with and without 
fragile $\mathrm{X}$-associated tremor/ataxia syndrome (FXTAS). J Psychiatr Res 2011;45(01):36-43

55. Moser C, Schmitt L, Schmidt J, Fairchild A, Klusek J. Response inhibition deficits in women with the FMR1 premutation are associated with age and fall risk. Brain Cogn 2021;148:105675

56. Klusek J, Hong J, Sterling A, Berry-Kravis E, Mailick MR. Inhibition deficits are modulated by age and CGG repeat length in carriers of the FMR1 premutation allele who are mothers of children with fragile $\mathrm{X}$ syndrome. Brain Cogn 2020;139:105511

57. Kraan CM, Hocking DR, Georgiou-Karistianis N et al. Impaired response inhibition is associated with self-reported symptoms of depression, anxiety, and ADHD in female FMR1 premutation carriers. Am J Med Genet B Neuropsychiatr Genet 2014; 165B(01):41-51

58. Shelton AL, Cornish KM, Kraan CM, Lozano R, Bui M, Fielding J. Executive dysfunction in female FMR1 premutation carriers. Cerebellum 2016;15 (05):565-569

59. Klusek J, Porter A, Abbeduto L et al. Curvilinear association between language disfluency and FMR1 CGG repeat size across the normal, intermediate, and premutation range. Front Genet 2018;9:344

60. Hasher L, Zacks RT. Working memory, comprehension, and aging: a review and a new view. Psychol Learn 1988;22:193-225

61. Bredin-Oja SL, Warren SF, Swinburne Romine RE, Fleming KK, Brady N, Berry-Kravis E. Word retrieval difficulty in adult females with the FMR1 premutation: changes over time and across contexts. Brain Cogn 2021;148:105694

62. Seltzer MM, Abbeduto L, Greenberg JS, Almeida D, Hong J, Witt W. Biomarkers in the study of families of children with developmental disabilities. Int Rev Res Ment Retard 2009;37:213-249

63. Bailey DB Jr, Raspa M, Bishop E, Holiday D. No change in the age of diagnosis for fragile $\mathrm{x}$ syndrome: findings from a national parent survey. Pediatrics 2009;124(02):527-533

64. McDuffie A, Machalicek W, Bullard L et al. A spoken-language intervention for school-aged boys with fragile $\mathrm{X}$ syndrome. Am J Intellect Dev Disabil 2016;121(03):236-265

65. Thurman AJ, Potter LA, Kim K et al. Controlled trial of lovastatin combined with an open-label treatment of a parent-implemented language intervention in youth with fragile $\mathrm{X}$ syndrome. J Neurodev Disord 2020;12(01):12

66. McDuffie A, Banasik A, Bullard L et al. Distance delivery of a spoken language intervention for school-aged and adolescent boys with fragile X syndrome. Dev Neurorehabil 2018;21(01): 48-63

67. Hartley SL, Seltzer MM, Raspa M, Olmstead M, Bishop E, Bailey DB. Exploring the adult life of men and women with fragile $\mathrm{X}$ syndrome: results from a national survey. Am J Intellect Dev Disabil 2011;116(01):16-35

68. Brady NC, Bruce S, Goldman A et al. Communication services and supports for individuals with severe disabilities: guidance for assessment and intervention. Am J Intellect Dev Disabil 2016; 121(02):121-138

69. National Joint Committee for the Communication Needs of Persons With Severe Disabilities Access to communication services and supports: Concerns regarding the application of restrictive "eligibility" policies [Technical Report]. American SpeechLanguage and Hearing Association. Published 2002at: www.asha.org/policy

70. Martin GE, Ausderau KK, Raspa M, Bishop E, Mallya U, Bailey DB Jr. Therapy service use among individuals with fragile $\mathrm{X}$ syndrome: findings from a US parent survey. J Intellect Disabil Res 2013;57 (09):837-849

71. Roberts JE, Ezell JE, Fairchild AJ et al. Biobehavioral composite of social aspects of anxiety in young adults with fragile $\mathrm{X}$ syndrome contrasted to autism spectrum disorder. Am J Med Genet B Neuropsychiatr Genet 2018;177(07):665-675

72. Mailick MR, Hong J, Greenberg J, Smith L, Sherman S. Curvilinear association of CGG repeats and age at menopause in women with FMR1 premutation expansions. Am J Med Genet B Neuropsychiatr Genet 2014;165B (08):705-711 